\title{
Prediction of Flash Formed in Plastic Injection Molding Using Aluminum Alloy Mold Cavity by Numerical Simulation Considering Deformation of Mold Parts
}

\author{
Makoto Nikawa, ${ }^{1 *}$ Hiroki Shibata, ${ }^{2}$ Keisuke Hatanaka, ${ }^{2}$ and Minoru Yamashita ${ }^{1}$ \\ ${ }^{1}$ Faculty of Engineering, Gifu University, \\ 1-1 Yanagido, Gifu 501-1193, Japan \\ ${ }^{2}$ Graduate School of Engineering, Gifu University, Gifu 501-1193, Japan
}

(Received March 7, 2019; accepted July 4, 2019)

Keywords: injection molding, computer simulation, mold deformation, flash, aluminum alloy mold

In this study, we examined a method of predicting the flash formed in plastic injection molding via computer simulations. The gap between molds was calculated by mold deformation simulation, and the results were compared with the actual flash thickness. The molding test was performed using a mold manufactured from steel and aluminum alloy. The pressure and temperature on the cavity surface during molding were measured using a measurement sensor. An injection molding simulation based on the actual pressure and temperature was carried out, and the results were mapped to the elements of a finite element (FE) model for mold deformation analysis. In this model, a mold equipped with a molding machine was used for the mold deformation analysis. The results of the mold deformation analysis were in good agreement with the actual results. The flash thickness with the product molded with an aluminum alloy mold was smaller than that with a steel mold. The calculated gap amount and the position of its generation correlated with the actual formed flash. The possibility of the present method for predicting flash formation was demonstrated.

\section{Introduction}

In the field of injection molding, there is a need to produce various products in small amounts as with other manufacturing industries. In addition, there is currently a demand to improve the product accuracy, shorten the cycle time, and reduce the manufacturing cost. Various molding processing technologies, molding machines, and computer simulations have been developed and put to practical use in order to meet this demand, but there are limitations on shapes that can be molded, the cost of equipment is increasing, and the establishment of a technology with greater versatility is required.

To reduce the cycle time, it is effective to reduce the production time of a mold for injection molding and the molding time. Many machining processes such as cutting and electric discharge machining are used to produce molds, so it is important to shorten the machining

*Corresponding author: e-mail: mniikawa@gifu-u.ac.jp

https://doi.org/10.18494/SAM.2019.2362 
time. The reduction in cooling period during molding is effective for reducing the molding time. ${ }^{(1)}$ Aluminum alloys have good machinability ${ }^{(2)}$ and thermal conductivity. ${ }^{(3)}$ These characteristics are helpful for reducing the cycle time, and these alloys have great potential as mold materials for resin injection molding. ${ }^{(4-7)}$ Generally, molds manufactured from an aluminum alloy are used in trial manufacturing and low-volume molding with simple shapes. However, there is a report that such molds were used for mass production.

For high-precision molding, it is extremely important to determine the deformation state of the mold during molding. Factors affecting the deformation of the mold exist inside and outside of the mold. The internal factors included the heat of molten resin, the injection pressure, and the dwelling pressure. The external factors are the clamping force and the heat of the coolant used to control the mold temperature. Furthermore, the structures of the molding machine and mold can be considered as factors causing mold deformation. Mold deformation occurs as a result of various factors acting together. Therefore, in order to guarantee the accuracy of molded products from the viewpoint of the mold, it is necessary to analyze multiple phenomena in the mold during molding via various sensors and to establish a prediction method via computer simulation that utilizes the measured data. ${ }^{(8-10)}$

In order to achieve sophisticated high-functionality injection molding utilizing molds manufactured from an aluminum alloy, it is necessary to examine the appearance of the molded product, mechanical properties, and molding failure. The causes of molding failure can be classified as follows:

(1) flow and solidification of molten resin (e.g., a weld line, warpage, or sink) and

(2) mold deformation (e.g., flash or dimensional variation).

The present study focuses on flash, which is a molding failure caused by the deformation of the mold. ${ }^{(11-13)}$ Flash is formed by molten resin flowing into a gap generated by mold deformation. The lower hardness of molds manufactured from aluminum alloys than of molds manufactured from steel tends to result in greater deformation during injection molding, and the generation of a gap between the mold parting faces is a problem occurring in molds with an inappropriate design.

This study was carried out to predict mold deformation by finite element (FE) simulation. Mold deformation was analyzed on the assumption that it is important to consider the structure of the molding machine for highly accurate prediction. ${ }^{(14-18)}$ On the basis of this consideration, the maximum gap between the mold parting faces when the resin was completely filled in the mold was calculated. Furthermore, the possibility of predicting the formation of flash in a molded product was examined by comparing the gap with the flash thickness.

\section{Experimental Procedure}

\subsection{Injection molding tests}

A two-plate mold consisting of a fixed side and a movable side was used for the molding test. The product had an insert mold, which was installed into a matrix with a rectangular hole. Steel (JIS-S50C) was used as the matrix material, and steel (hereinafter called the steel mold) and 
7000 series aluminum alloy (hereinafter called the aluminum alloy mold) were used as insert mold materials. The size tolerances of these insert molds were the same, and the clearance between the matrix and the insert mold was set to be the same as that when the insert mold was installed into the matrix. Figure 1 shows a schematic drawing of the molded product and Fig. 2 shows the mold.

A molding test was carried out using an injection molding machine (capacity of $1080 \mathrm{kN}$ ) equipped with a mold, and the mold temperature was controlled by flowing a coolant at $50{ }^{\circ} \mathrm{C}$ into the mold. The molding test was carried out after the mold temperature reached a steady state. Table 1 shows the molding conditions. The surface temperature and internal pressure of the mold cavity were measured continuously during the molding process at P1 and P2 (see Fig. 1). As the device for measuring the temperature and internal pressure, a cavity pressure and temperature measurement sensor (6190CA, Kistler Instrument AG) was used.

\subsection{Evaluating mold deformation state}

\subsubsection{Contact state of mold parting plane}

The contact state of the mold parting face when a clamping force was applied was observed. To evaluate the effect of the structure of the molding machine on mold deformation without thermal deformation (in other words, when the mold temperature was room temperature), a

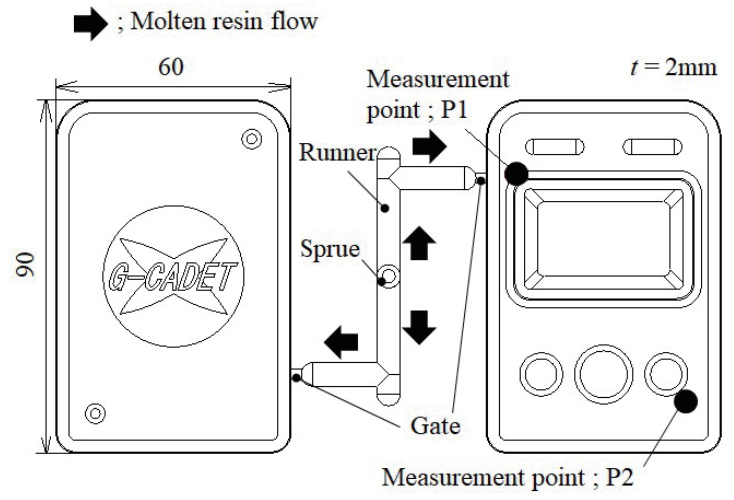

Fig. 1. Schematic drawing of the molded product.

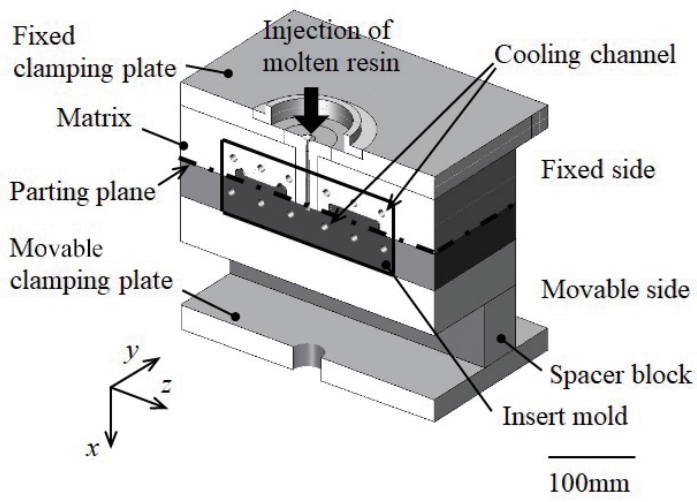

Fig. 2. Schematic drawing of the mold.

Table 1

Molding conditions.

\begin{tabular}{lc}
\hline Parameters & Value \\
\hline Resin temperature $\left({ }^{\circ} \mathrm{C}\right)$ & 230 \\
Filling and dwelling time (s) & 8 \\
Cooling time $(\mathrm{s})$ & 18 \\
Filling speed $(\mathrm{mm} / \mathrm{s})$ & 40 \\
Setting value of dwelling pressure of molding machine $(\mathrm{MPa})$ & $80,90,100,110$ \\
V-P switching position $(\mathrm{mm})$ & 10 \\
\hline
\end{tabular}


pressure measurement film (PRESCALE MS, Fujifilm Corporation) was affixed on the mold parting face, and the mold deformation state was established from the pressure distribution when the mold was closed by applying a clamping force. The clamping force was set to 10 or $100 \%$ of the machine capacity, and the contact state was evaluated by the light and shade of the pressure measurement film after mold clamping.

\subsubsection{Distortion of mold during molding}

To evaluate the mold deformation quantitatively, the strain of the mold during molding was measured with a strain gage. Strain was continuously measured along the $Y$-axis $(\mathrm{CH} 1, \mathrm{CH} 2)$ and $X$-axis $(\mathrm{CH} 3, \mathrm{CH} 4)$ by strain gages affixed on the back plate in the movable mold and near the parting plane. Figure 3 shows photographs of the mold with strain gages. First, the mold temperature was set to room temperature and the strains of the mold were measured with various mold clamping forces (hereinafter called test A). Secondly, the mold temperature was set to $50{ }^{\circ} \mathrm{C}$ and the strains were measured by the same test (hereinafter called test B). The clamping force was set to 10,50 , or $100 \%$ of the machine capacity.

\subsection{Evaluating formation of flash}

Flash is formed by molten resin flowing into a gap generated by the mold deformation. Therefore, a molding test in which flash was formed intentionally in the molded product was carried out by changing the holding pressure during injection molding. The flash was evaluated in terms of its thickness and the location where it formed. The flash thickness was measured using a micrometer, and the location of flash formation was visually confirmed.

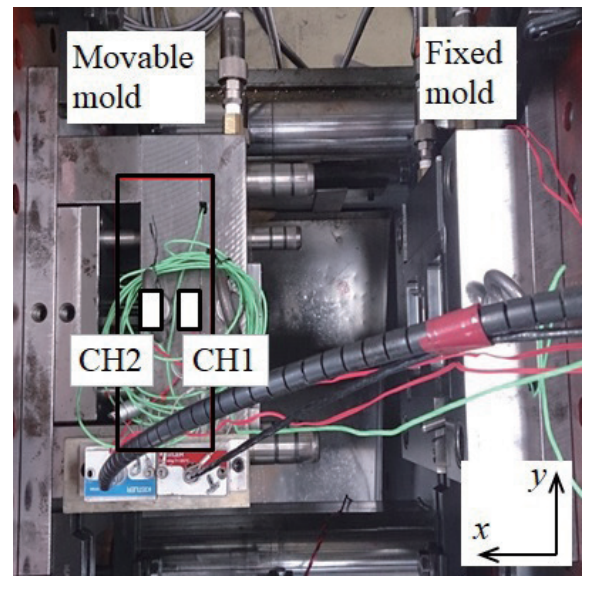

(a)

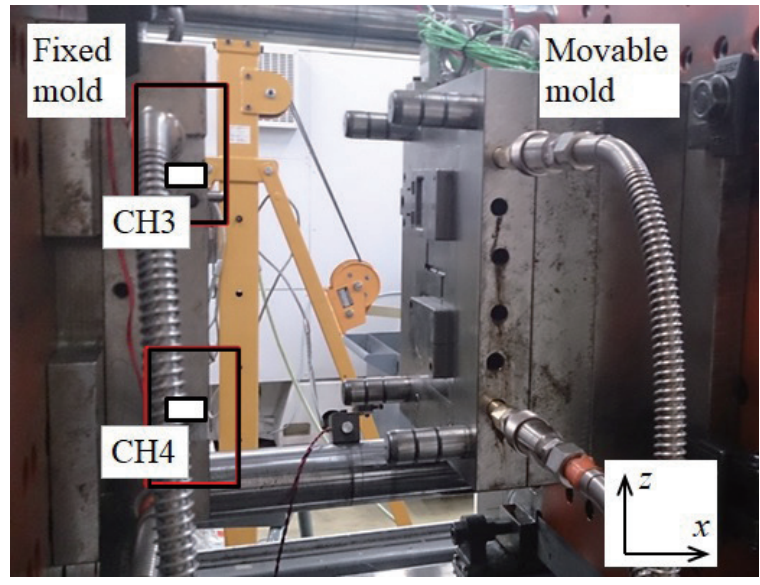

(b)

Fig. 3. (Color online) Experimental setup showing the strain gages attached to the mold: (a) top and (b) side views. 


\section{Computer Simulation}

\subsection{Injection molding simulation}

The distributions of the mold temperature and internal pressure were computed via injection molding simulation software (Moldflow Insight 2014, Autodesk Inc.). Figure 4 shows the simulation model of the molded product and cooling channel. The molded product model consisted of a sprue, a runner, gate, and a product, and the tip of the sprue was installed as an injection point. Table 2 shows the calculation conditions of the injection molding simulation. The setting dwelling pressure in this simulation was adjusted so that the simulated maximum internal pressure of the mold was the same as the measured pressure at P1 and P2. In other words, the dwelling pressure input to the molding machine was different from the setting value in the simulation software. Figure 5 shows the relationship between the setting dwelling pressure in the computer simulation and the setting dwelling pressure in the molding machine. The distribution of the mold temperature was calculated for different values of the heat transfer coefficient in the resin filling, dwelling, and mold release processes.

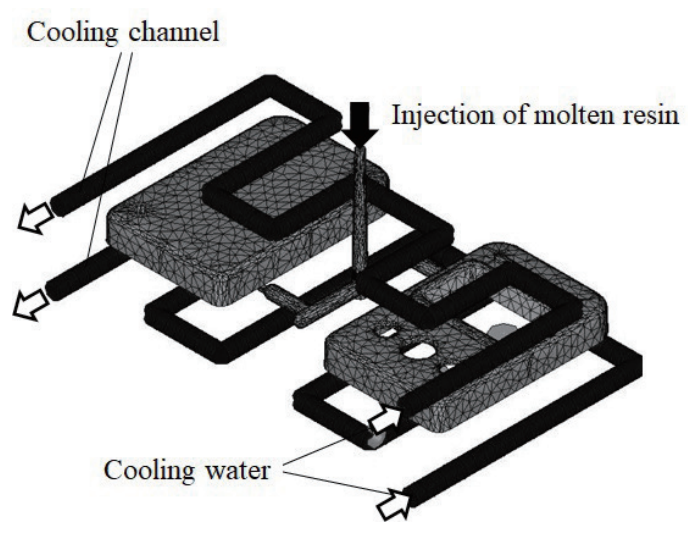

Fig. 4. Simulation model for molding simulation.

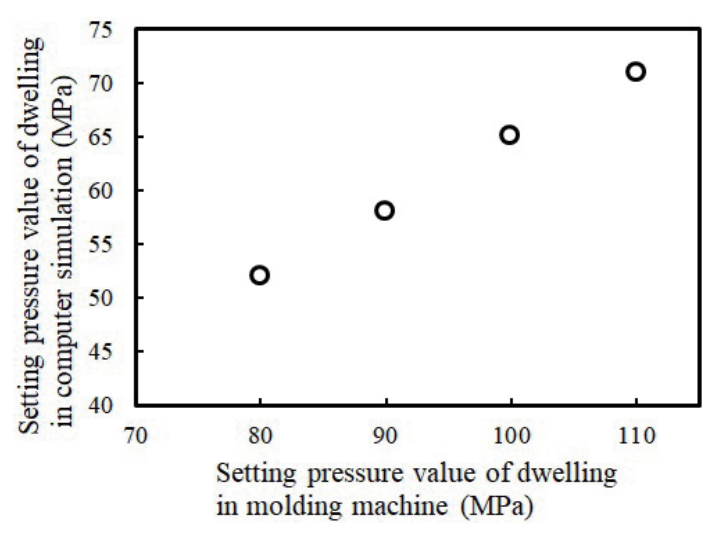

Fig. 5. Relationship between setting dwelling pressure in the computer simulation and setting dwelling pressure in the molding machine.

Table 2

Calculation conditions of injection molding simulation.

\begin{tabular}{lc}
\hline Parameters & Value \\
\hline Resin temperature $\left({ }^{\circ} \mathrm{C}\right)$ & 230 \\
Filling and dwelling time $(\mathrm{s})$ & 8 \\
Cooling time $(\mathrm{s})$ & 18 \\
Filling speed $(\mathrm{mm} / \mathrm{s})$ & 40 \\
Dwelling pressure $(\mathrm{MPa})$ & $52,58,65,71$ (see in Fig. 5) \\
V-P switching position $(\mathrm{mm})$ & 10 \\
Mold temperature $\left({ }^{\circ} \mathrm{C}\right)$ & 50 \\
Mesh shape & Tetrahedron \\
& (Filling) 5000 \\
Heat transfer coefficient between mold surface and resin $\left(\mathrm{W} / \mathrm{m}^{2} \mathrm{~K}\right)$ & (Dwelling) 2500 \\
& (Mold release) 1250 \\
\hline
\end{tabular}




\subsection{Mold deformation analysis}

The mold deformation was computed with ANSYS Workbench Mechanical Ver. 14.0. Figure 6 shows a simulation model in which the mold is equipped with the molding machine used for mold deformation analysis. The calculated results of the injection molding simulation were mapped to elements of the FE model for mold deformation analysis. Constraint conditions between the components of the molding model were set in order to simulate the actual movement of the molding machine. The mold clamping was reproduced by setting a load corresponding to the clamping force in the toggle joints.

\section{Results}

\subsection{Flash formation}

Figure 7 shows the appearance of the molded product. Flash was formed along the runner when the dwelling pressure was increased. This result suggests that a gap was generated at the center between the molds and the flash was formed.

Figure 8 shows the relationship between the flash thickness and the dwelling pressure. The flash thickness increased with the dwelling pressure. The flash thickness obtained by molding with the aluminum alloy mold was smaller than that when the steel mold was used.

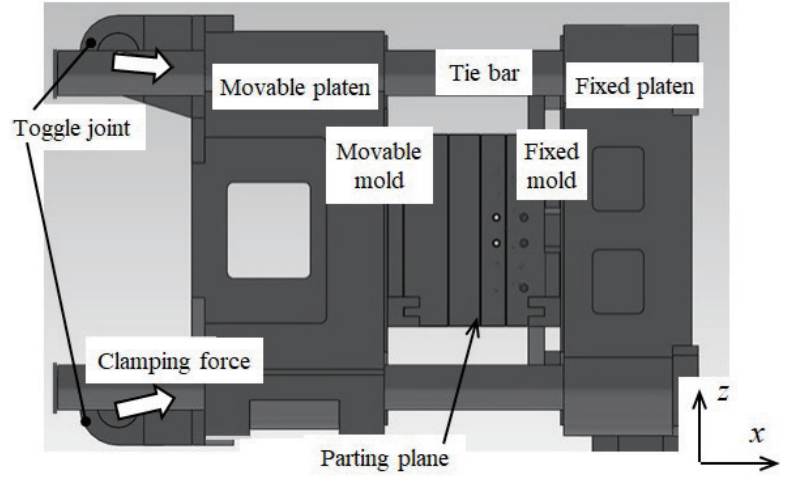

Fig. 6. Simulation model in which the mold is equipped with the molding machine used for mold deformation analysis.

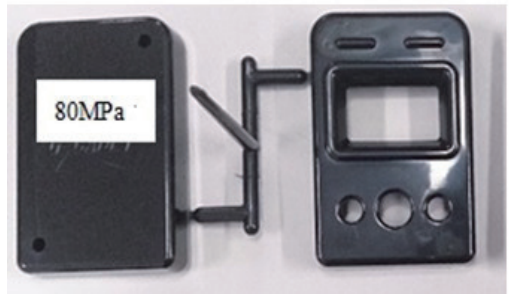

(a)

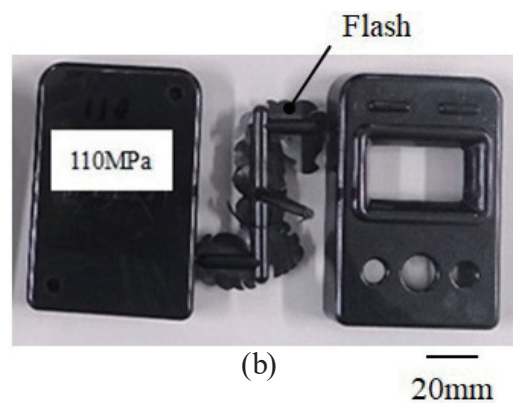

Fig. 7. Molded products for dwelling pressures of (a) 80 and (b) $110 \mathrm{MPa}$. 


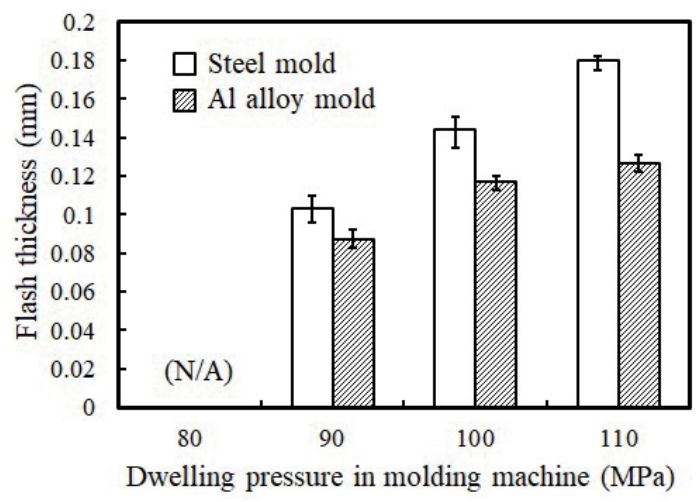

Fig. 8. Relationship between the flash thickness and the dwelling pressure.

\subsection{Pressure on cavity and temperature during molding}

Figure 9 shows the actual and calculated pressures on the cavity. The pressure was largest when the resin completely filled the mold and gradually decreased with increasing molding time. Although the calculated results were similar, there was a difference in the rate of decrease in pressure. This is expected to be due to the inability to perform molding simulation considering the deformation of the mold and molded product during molding.

Figure 10 shows the actual and calculated mold temperatures. The maximum difference between the calculated and actual values was approximately $15^{\circ} \mathrm{C}$. The difference between the calculated temperatures $\mathrm{T} 1$ and $\mathrm{T} 2$ was approximately the same as the actual difference.

\subsection{Mold deformation state}

Figure 11 shows the actual and calculated contact states of the mold parting face. In the actual results, the color contrast was almost uniform when the mold clamping force was $100 \%$, but in the case of a clamping force of $10 \%$, the color in the lower area was dark. This result suggests that the parting face was strongly in contact with the lower part. According to the calculated results, the pressure at the bottom of the parting face was higher than elsewhere, which is in agreement with the actual results.

Figure 12 shows the strain when the resin completely filled the mold in test A. The actual strain changed with the clamping force, but its direction did not change. The maximum error of the calculated values compared with the actual values was approximately $20 \%$, but the strain directions were consistent.

Figure 13 shows the strain when the resin completely filled the mold in test $\mathrm{B}$. The direction of the actual strain of $\mathrm{CH} 3$ and $\mathrm{CH} 4$ changed with the magnitude of the clamping force, and the calculated results were similar to the actual values.

Figure 14 shows the calculated gap generation state between the molds at the dwelling pressure of $110 \mathrm{MPa}$. A large gap was generated in the central area of the insert mold. The gap for the aluminum alloy mold was smaller than that for the steel mold. 


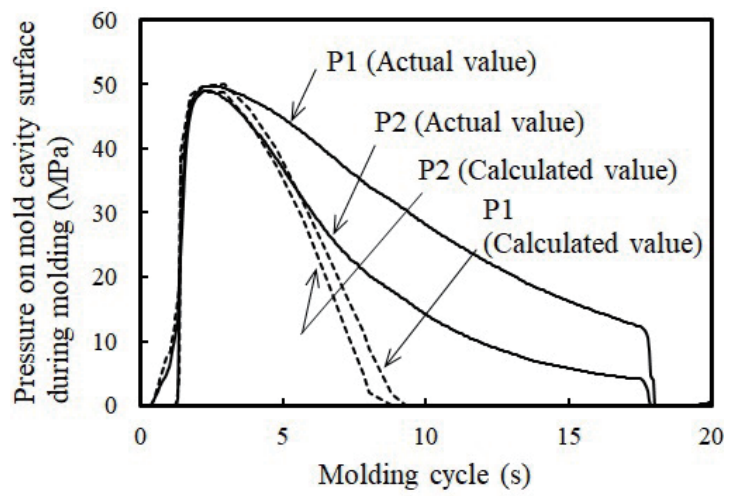

Fig. 9. Actual and calculated pressures on the cavity.

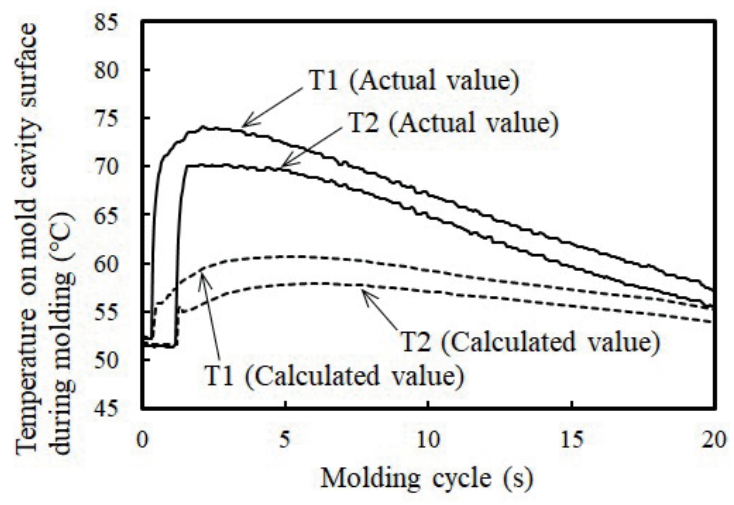

Fig. 10. Actual and calculated mold temperatures.

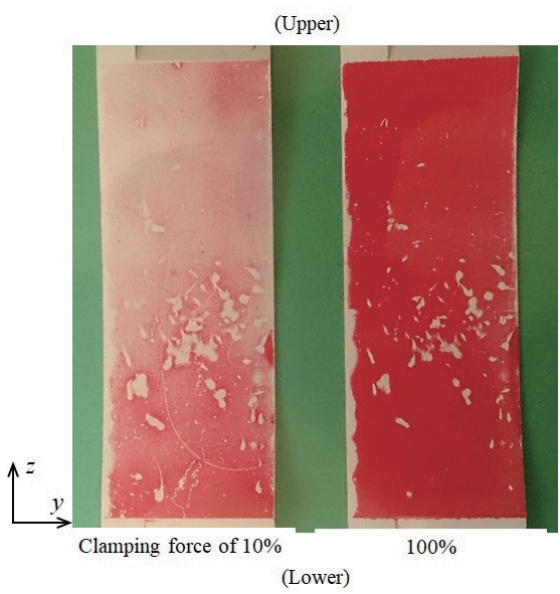

(a)

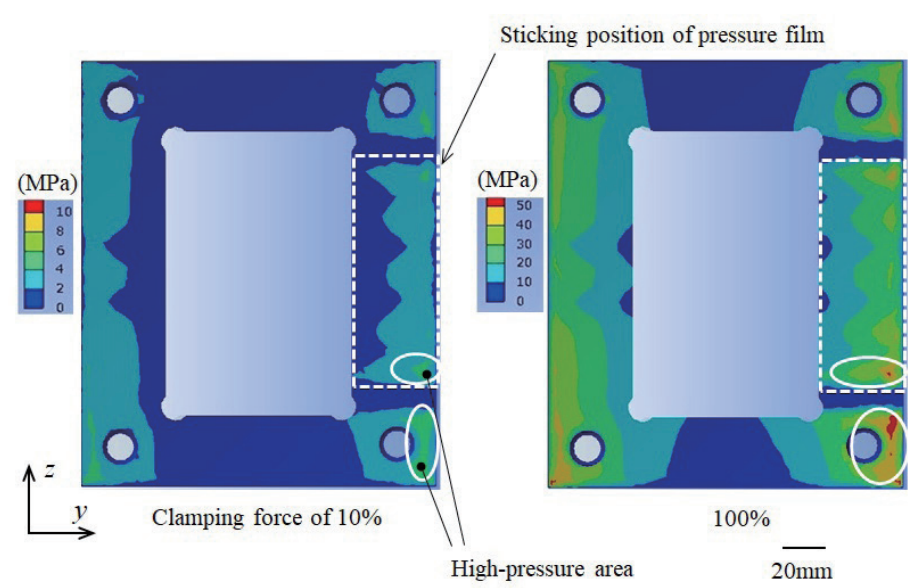

(b)

Fig. 11. (Color online) Actual and calculated contact states of the mold parting face: (a) measured results obtained by pressure measurement film and (b) calculated results obtained by FE simulation.

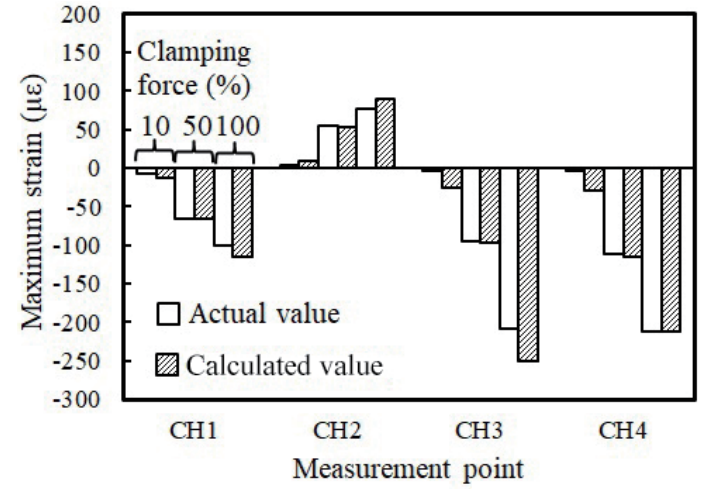

Fig. 12. Actual and calculated maximum strains in test A.

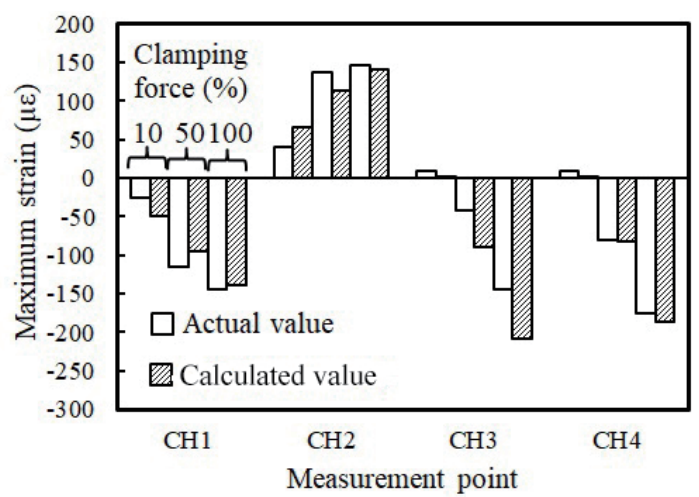

Fig. 13. Actual and calculated maximum strains in test $\mathrm{B}$. 


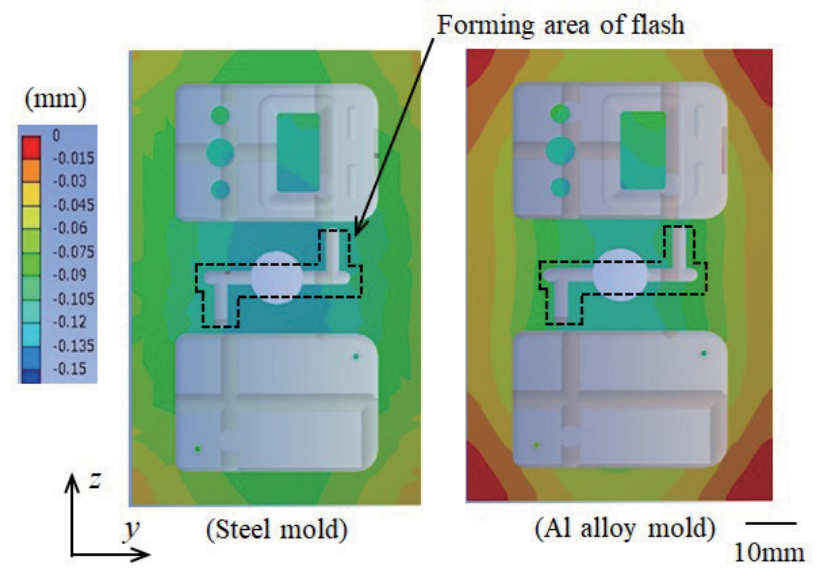

Fig. 14. (Color online) Calculated gap generation state for different mold materials.

Figure 15 shows the calculated gap as a function of the dwelling pressure in the molding machine for the two mold materials. The gap increased with the dwelling pressure. The gap for the aluminum alloy mold was approximately 20 to $30 \%$ smaller than that with the steel mold.

Figure 16 shows the actual flash thickness as a function of the gap between the molds for both mold materials. The thickness of the flash was greater than the gap, but they correlated with each other.

\section{Discussion}

The aim of this study was to establish a method of predicting the formation of flash in a molded product. An ideal prediction method is to directly simulate the state in which flash is formed by molten resin flowing into the gap between the mold parting faces caused by mold deformation. The flowing molten resin is rapidly solidified in the part in contact with the mold, and a melt region that exists inside the solidified layer flows through the gap. Therefore, it is necessary to exactly calculate the changes in mold and molded product temperatures and to simulate the change in pressure transmitted from the sprue accompanying the growth of the solidified layer in the molded product. ${ }^{(19,20)}$ In addition, the mechanical and physical properties are unstable owing to the resin and the molding pressure changing continuously. ${ }^{(21)}$ Thus, largescale analysis in which the mold deformation and resin flow analyses are linked is an important task, but it is necessary to examine in detail the phenomena in the mold during injection molding.

Therefore, this study focused on the calculated gap between the molds, and the possibility of indirectly predicting the formation of flash from the result of the mold deformation analysis was examined. In this study, the actual location of flash formation and the thickness of the flash approximately corresponded to the calculated location and gap (Figs. 7, 14, and 16). Furthermore, the flash thickness was measured at room temperature, and the calculated gap was attributed to the thermal expansion of the mold. Thus, in order to consider the exact 


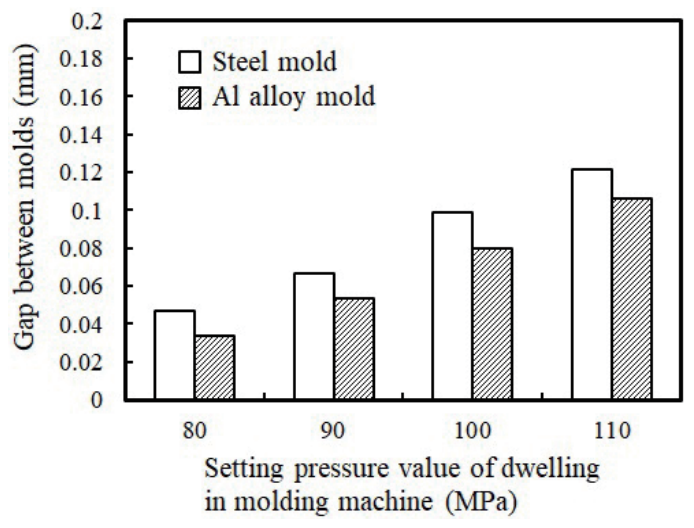

Fig. 15. Calculated gap as a function of the setting pressure of dwelling in the molding machine for $\mathrm{Al}$ alloy and steel molds.

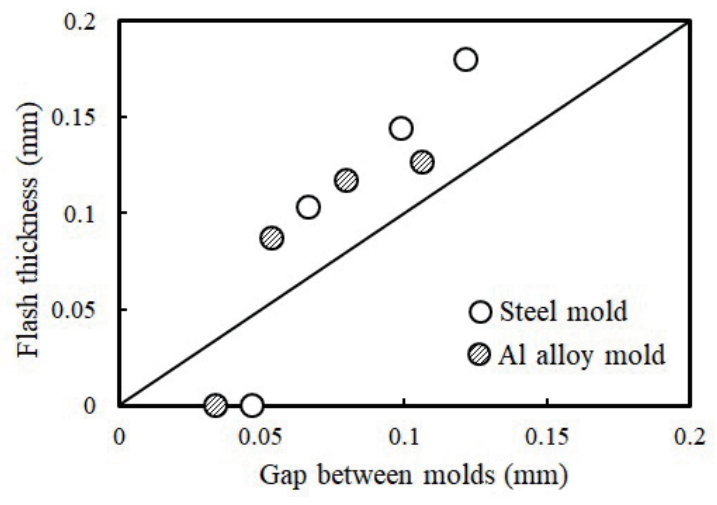

Fig. 16. Actual flash thickness as a function of the calculated gap for Al alloy and steel molds.

correspondence between the flash thickness and the gap amount of the mold, it is necessary to consider the thermal expansion of flash at high temperatures when flash is formed. However, the cavity surface temperature during molding was approximately $75{ }^{\circ} \mathrm{C}$ according to the temperature measurement sensor. It is assumed that the thickness of the ABS flash of 0.100 $\mathrm{mm}$ at room temperature increases to approximately $0.101 \mathrm{~mm}$ at $75{ }^{\circ} \mathrm{C}$, and the difference between these values is small. It is appropriate to compare the flash thickness at room temperature with the maximum gap during molding. Thus, it was possible to estimate the location of flash formation and the thickness of the flash from the calculated result obtained by mold deformation analysis.

The mold deformation state in the simulation closely matched the actual deformation state in this study (Figs. 11-13). Thus, the cause of the difference in gap with the mold material is based on this result. Figure 17 shows the back plate deflection for the steel and aluminum alloy molds. The deflection was larger in the aluminum alloy mold. There is a large space between the back plate and the platen, which allows the ejector plate to be moved to release the molded product. Therefore, the back plate is deflected during molding. From this result, it was inferred that the aluminum alloy mold was deflected more to the movable side and the gap became larger, but the actual gap was smaller.

Thus, the mold structure consisting of the matrix and insert mold is focused on. Figure 18 shows the calculated pressure distribution at the contact face between the matrix and the insert mold (i.e., the vertical bold line in Fig. 2). A contact pressure of approximately 40 to $50 \mathrm{MPa}$ in the $Y$-direction was calculated at the contact face near the mold parting face. On the other hand, the contact pressure was in the range from 10 to $30 \mathrm{MPa}$ in the steel mold. The following can be considered from these results. The insert mold manufactured from the aluminum alloy bulges towards the matrix owing to the aluminum alloy having a larger thermal expansion coefficient and a lower Young's modulus than steel. The hardness of the matrix manufactured from steel is greater than that of the insert mold, the deformation of the insert mold is restrained by the matrix, the insert mold elastically deforms towards the mold parting face, and the gap 


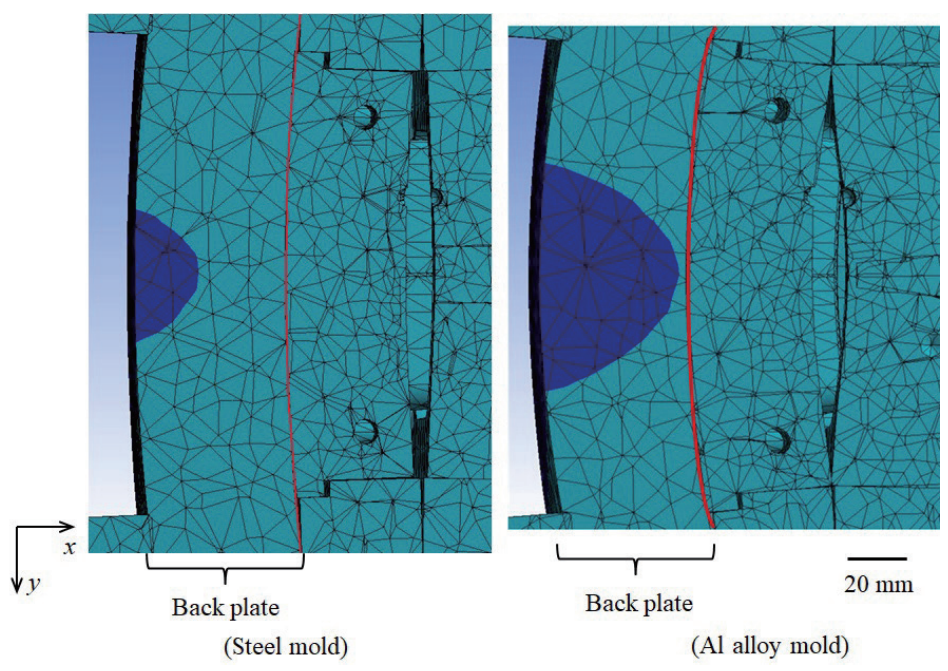

Fig. 17. (Color online) Calculated back plate deflection for the two molds.

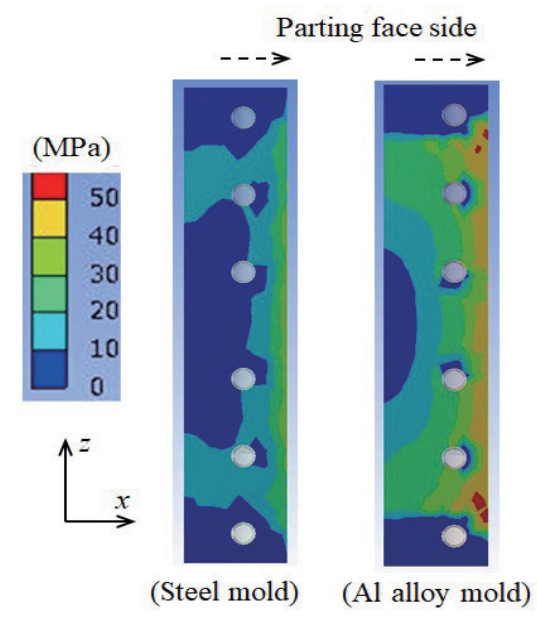

Fig. 18. (Color online) Calculated pressure distribution at the contact face between the matrix and the insert mold.

decreases. Different mold materials were used for the insert mold and matrix in this study, but a material with high thermal conductivity is generally used as the insert mold. These results suggest that sufficient consideration via computer simulation is required for the mold design when producing an injection molding mold with a combination of materials that have different mechanical properties such as aluminum alloy and steel.

Molds are important industrial tools that determine the shape accuracy and quality (e.g., mechanical properties) of industrial products. Therefore, it is strongly required to clarify the phenomenon that occurs during molding and to reflect the solution in the design of the mold. However, it is impossible to comprehend all phenomena that occur inside the mold during molding in real time. Furthermore, it is extremely difficult to constantly monitor the condition of the mold by installing a number of sensors (i.e., hard sensors) inside the mold used for mass 
production. One of the solutions is to use artificial intelligence (AI) and estimation models of phenomena (i.e., soft sensors). In order to improve the accuracy of this soft sensor, it is essential to acquire numerous highly accurate data using hard sensors.

In this study, to predict flash formation in the injection molding product, we examined a method of estimating the gap between the parting faces considered to be strongly related to the formation of flash by computer simulation. In this method, the location and thickness of flash that are difficult to measure directly are estimated by computer simulation based on the results obtained by a number of hard sensors. In other words, we believe this method to be a soft sensor in a broad sense.

To improve the accuracy of the estimated results in this study, it is necessary to consider a more detailed analysis of the fluid state and the solidification stage of the molten resin in the mold, and the state change in the plasticization of molten resin. However, it is also extremely difficult to measure them using hard sensors.

To achieve an advanced mold design, it is essential to understand the principle of mold and molding phenomenon. For that purpose, we think that it is effective to clarify the factor that controls the phenomenon in the actual mold and to intentionally create the reference point, which correlates with the factor and can be easily measured. Moreover, it is useful to analyze the reference point in detail.

\section{Conclusions}

In this study, the prediction method for the flash formed on the molded products was examined by calculating the gap between the mold parting faces. A comparative molding experiment using a steel mold and an aluminum alloy mold was performed, the state of the mold during molding was measured using various sensors, and a model for mold deformation analysis was examined on the basis of the obtained results. The validity of the present method was examined by calculating the gap between the molds using the analytical model and comparing it with the flash thickness of the molded products. The following results were obtained:

(1) The mold deformation analysis simulated the actually measured results by considering the structure of the molding machine.

(2) The calculated gap between the molds manufactured from the aluminum alloy was smaller than that from the steel.

(3) The calculated gap between the molds correlated with the actually formed flash.

(4) If different materials are used for mold parts, it is assumed that the mold deformation will be large owing to the differences in the physical properties of the mold materials, so a detailed examination of the design process is necessary.

\section{References}

1 M. Nikawa, Y. Matsui, H. Yamagata, M. Kinoshita, T. Yamawaki, and W. Oikawa: J. JSTP 54 (2013) 247 (in Japanese).

2 E. W. Thiele, K. J. A. Kundig, D. W. Murphy, G. Saloway, and B. Duffin: SAE Trans. J. Mater. Manuf. 99 (1990) 5. https://doi.org/10.4271/900365 
3 ASME Handbook Metals Properties, Samuel L. Hoyt, Ed. (McGraw-Hill Book Company Publishing, New York, 1954) pp. 341-353.

4 H. Yamagata, S. Takai, M. Nikawa, and W. Oikawa: J. JSTP 53 (2012) 125 (in Japanese).

5 M. Nikawa, Y. Matsui, H. Shibata, H. Yamagata, and W. Oikawa: Proc. Asian Workshop on Polymer Processing 2012 (AWPP, 2012) 309-310.

6 M. Nikawa, Y. Matsui, H. Yamagata, and W. Oikawa: Proc. 15th Int. Conf. Precision Engineering (ICPE, 2014) 871-875.

7 M. Nikawa, K. Hatanaka, H. Kondo, T. Furuhashi, S. Higuchi, and H. Nanya: Proc. 16th Int. Conf. Precision Engineering (ICPE, 2016) P16-8226.

8 T. Murotani: Die Mould Technol. 27 (2012) 26 (in Japanese).

9 H. Koresawa, H. Suzuki, T. Takenaka, and S. Kinjo: Trans. Jpn. Soc. Mech. Eng. Ser. C 63 (1997) 2144.

10 M. Nikawa, T. Shirota, and H. Yamagata: Int. J. Automat. Technol. 10 (2016) 1. https://doi.org/10.20965/ ijat.2016.p0094

11 Y. Murata, H. Hashimoto, Y. Hara, T. Shimizu, R. Shibasaki, K. Nitta, and K. Kikumori: J. Jpn. Soc. Polym. Process. 25 (2013) 234 (in Japanese).

12 Y. Murata, T. Inoue, and T. Fujibayashi: Int. J. Automat. Technol. 11 (2017) 1. https://doi.org/10.20965/ijat.2017. p0090

13 Z. Chen, A. J. Giacomin, and L. Turng: Polym. Eng. Sci. 46 (2006) 3. https://doi.org/10.1002/pen.20467

14 H. Yamagata, Y. Shigenaga, S. Tanikawa, and M. Nikawa: Trans. Jpn. Soc. Mech. Eng. Ser. C 79 (2013) 3920 (in Japanese).

15 A. K. Choudhury, S. Dedhia, H. Ahuett-Garza, and R. A. Miller: NADCA Trans. (1997) 103.

16 A. Chayapathi, V. Kesavan, and R. A. Miller: Die Cast. Eng. 44 (2000) 60.

17 B. Carpenter, S. Patil, R. Hoffman, B. Lilly, and J. Castro: Polym. Eng. Sci. 46 (2006) 7. https://doi. org/10.1002/pen.20527

18 C.-H. Wu and Y.-J. Huang: Int. J. Adv. Manuf. Technol. 32 (2007) 1144. https://doi.org/10.1007/s00170-0060435-4

19 A. Kumar, P. S. Ghoshdastidar, and M. K. Muju: J. Mater. Process. Technol. 120 (2002) 438.

20 T. Hirai, T. Katayama, M. Hirai, and M. Tsunezawa: J. Soc. Mater. Sci. Jpn. 38 (1989) 334 (in Japanese).

21 S. Sato and Y. Oyanagi: J. Jpn. Soc. Polym. Process. 3 (1991) 351 (in Japanese).

\section{About the Authors}

Makoto Nikawa received his B.S., M.S., and Ph.D. degrees in mechanical engineering in 1998, 2000, and 2003, respectively, from the University of Fukui, Japan. Currently, he is an associate professor at Gifu University, Japan. His research interests include die- and mold-based casting, injection molding, and precision cutting applications. (mniikawa@gifu-u.ac.jp)

Hiroki Shibata received his B.S. and M.S. degrees in mechanical engineering from Gifu University, Japan, in 2011 and 2013, respectively. Currently, he works for a private company.

Keisuke Hatanaka received his B.S. and M.S. degrees in mechanical engineering from Gifu University, Japan, in 2011 and 2013, respectively. Currently, he works for a private company.

Minoru Yamashita received his B.S., M.S. and Ph.D. degrees in mechanical engineering from Gifu University, Japan, in 1986, 1988, and 1999, respectively. He worked as an engineer in a company from 1988 to 1991 . Since 2014, he has been a professor at Gifu University. His research interests are in high-strain rate deformation and structural impact.

(minoruy@gifu-u.ac.jp) 